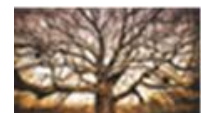

AVRASYA Uluslararası Araştırmalar Dergisi Cilt:5 •Sayı:11•Temmuz 2017•Türkiye

\title{
XIX YÜZYILIN SONU XX YÜZYILIN BAŞLARINDA NAHÇIVAN'DA MESCID OKULLARI VE MEDRESELER
}

Öğr.Gör.Taleh HALILOV*

\section{Öz}

Makalede XIX yüzyılın sonu XX yüzyılın başlarında Nahçıvan'da mescid okulları ve medreselerı incelenmiş ve araştırılmıştır. Bu zaman öğrenilmiştir ki, XIX yüzyılın 60'lı yıllarında ülkede geniş kapsamı almış aydınlanma hareketi Nahçıvan'a da hayli etkilemiştir. Öyle ki, Nahçıvan kazasında ve bölgelerinde faaliyet gösteren okullarda öğrencilerin sayısı artmış, okul kütüphaneleri oluşturulmuş, resim, jimnastik, Latince meşğaleleri, tarım ve sanat derslerinin geçilmesine başlanmıştı. Bu dönemde Nahçıvan'da medeni-maarif ocakları düzenlenmiş ve okullarda laik bilimler öğretilmiştir. Nahçıvan bölgesinin maarifperver aydınları Azerbaycan'ın aydınlanma tarihine büyük katkılar vermişlerdir.

XIX yüzyılın sonu XX yüzyılın başlarında Nahçıvan'da faaliyet gösteren mədrəslər okullardan bir basamak yukarı olarak görülüyordu. Daha net ifadeyle okullar şimdiki dönemle karşılaştırıldığında orta okulların, medreseler ise yüksek okulların işlevini yerine getiriyordu. Ayrıca okullar medreselere hazırlık oluşturuyordu. Öyle ki, çocuklar medreselerde eğitim alamıyorlardı.

Şunu da belirtelim ki, 1893 yılında okul ve medreselere yönetim kurallarında biraz değişiklik oldu. Öyle ki, bu kanuna göre Azerbaycan'da olduğu gibi Nahçıvan bölgesinde de faaliyet gösteren tüm okul ve medreseler genel idari organlara dahil edildi. Daha tam olarak, bu kanundan sonra okul ve medreseler bilavastə valilerin idaresine verildi.

Anahtar Kelimeler: Nahçıvan, okul, eğitim, medrese, öğrenci

\section{MESCID SCHOOLS AND MEDRESTERS IN NAHCIVAN AT THE END OF THE XX CENTURY AND XIX CENTURY}

\begin{abstract}
Mescid schools and madrasahs in Nakhichevan at the beginning of the XXth century in the late nineteenth century were examined in this paper. It is learnt that the enlightenment movement in the country during the 60 's of the XIX century also greatly influenced Nakhichevan. The number of students increased in schools of Nakhchivan, school libraries were established; painting, gymnastics, Latin interests, agriculture and arts courses started to take place. In this period, contemporary-education was organized in Nakhchivan and secular sciences were taught in schools. The intellectuals of the Nahchevan region had great contributions to the history of Azerbaijan's enlightenment.

The end of the XIX century was seen as a step up from the early schools of Nakhichevan in the early 20th century. More precisely, schools were functioning as secondary schools when compared to the current period, while madrasahs were functioning as higher schools. In addition, the schools were preparatory to madrasah. Children were not be able to get training in the madrasahs.

It is important to point out that in 1893 there was a slight change in the rules of schools. According to this law, as in Azerbaijan, all the schools and madrasahs in Nakhchivan region were included in the general administrative bodies. More precisely, after this law, schools and madrasahs were appointed to the administration of the directly governors.
\end{abstract}

Keywords: Nakhchivan, school, education, madrasah, student

- Nahçıvan Devlet Üniversitesi, Yabancı Diller Bölümü, x.taleh@gmail.com 
XIX yüzyilin sonu $X X$ yüzyilin başlarında Nahçıvan bölgesinde yüzyıllar süren siyasi ve ruhani despotizm, fanatizm, cehalet ve bilgisizlik Nahçıvan'da halk eğitimi alanında reformlardan başlama gerekliliğini ön plana geçirmişti. Dönemin ünlü maarif adamı Mehmet Said buluyordu "maarif halkın yaşamını ve refahını yükseltiyor, onun islatçılıq qabliyyətini genişletiyor ve batıl inançtan kurtarıyor". Bütün bunlar öncelikle tədiqiq edilen dönemde Nahçıvan bölgesinde okulu halk hayatına yaklaştırmaya ve geniş halk kitlelerinin ana dilinde manevi taleplerine ve günlük intiyaçlarına uygun kurulmasını talep etmiştir. Kısıtlı okul ağına sahip olan inqilabaqədərki Nahçıvan'ın okullarında eğitim ve tatbikat daha çok dini karakter taşımıştı. Bu okullarda ana dilinin öğretimine yer verilmemiştir, tatbikat ise bireysel şekilde yapılmıştır. Gerek eğitim ve tatbikat, gerekse eğitim sınıfı nitelik taşıdığından işçi kitle bu okullardan istifade edememiştir. Böyle bir durum çok devam etmemiştir. Halk eğitiminin bu tür geriliğe mensup olduğu dönemde Nahçıvan'ın sosyal yaşamında belirgin değişiklikler ana verirmişdir. İlerici güçlerin gerici güçler üzerinde az zaferi hissetmiştir. Sosyal değişimlerle ilgili olarak eğitim ve kültür alanında oluşan yeni meyler halk eğitiminin gelişmesine zemin hazırlamıştır.

XIX yüzyilin sonu XX yüzyilin başlarında Kafkasya'nın tüm bölgelerinde olduğu gibi Nahçıvan'da da yaşayan müslümanların eğitim sistemi okul ve medreselerden ibaret olmuştur. XIX yüzyılın 70'li yıllarından sonra hükümet müslüman ruhani idarelerine, özellikle de okul ve medreselere ait ayrı yasa ve tüzük tertip etmiştir. Çar hükümeti kendi hükümranlığını becerdiği kadar güçlendirerek daha çok ruahnilərin faaliyetini kontrol altında tutmuştu.

$\mathrm{Bu}$ dönemde medreseler okullardan bir basamak yukarı hesap ediliyordu. Daha net söylersek okullar şimdiki dönemle kıyaslandığında orta okulların, medreseler ise yüksek okulların işlevini yerine getiriyordu. Ayrıca okullar medreselere hazırlık rolünü oynuyordu. Yüksek ruhani eğitimi almak ve medreselerde eğitimlerini sürdürmek isteyen tüm gençlerin okullarda okumaları önemliydi.

XIX yüzyılın sonu XX yüzyılın başlarında Nahçıvan'ın maarifperver aydınları halkı cehalet ve xürafat girdabın çıkarmak, halkın maariflenmesine ve kültürel gelişimine katkıda bulunmak yollarını arıyorlardı. XIX yüzyılın 60-70'li yıllarında halk maarifine sarf malzeme quberniyanın polise, gömürükxanaya ve devlet malını savunan idarelerin xerclerinden daha fazlaydı.

XIX yüzyılın sonu XX yüzyılın başlarında Nahçıvan bölgesinde asırlarca devam eden siyasi ve ruhani istibdad, bağnazlık, cehalet ve bilgisizlik Nahçıvan'da halk maarifi alanında reformlardan başlamak gerekliliğini ön plana geçirmişti. Dönemin önde gelen maarif rakamlar şöyle düşünüyorlardı ki, "maarif halkın meişetini ve refahını artırır, onun islatçılıq qabliyyetini genişletir ve mövhumatdan sürümüdür"

Tüm bunlar öncelikle tədiqiq olunan dönemde Nahçıvan bölgesinde okulu halk hayatına yaklaştırmaya ve geniş halk kitlelerinin anadilinde manevi şartları ve günlük ihtiyaçlarına uygun kurulmasını talep etmiştir. Sınırlı okul ağına sahip olan inqilabaqederki Nahçıvan'ın okullarında eğitim ve öğretim daha çok dini özellik taşımıştı. Bu okullarda ana dilinin öğretimine yer verilmemiştir, eğitim ise bireysel olarak yapılmıştır. İster öğretim ve eğitim, gerekse terbiye sınıfsal karakter taşıdığından zehmetkes kitle bu okullardan istifade edememiştir. Böyle bir durum çok devam etməişdir. Halk maarifinin bu tür gerilere mensup olduğu dönemde Nahçıvan'ın sosyal hayatında belirgin değişiklikler baş verirmiş. İlerici güçlerin gerici güçler 
üzerinde az çok zaferi fark edilmiştir. Sosyal değişikliklerle ilgili olarak maarif ve kültür alanında oluşan yeni meyler halk maarifinin gelişmesine imkan sağlamıştır.

\section{MEDRESE OKULLARI}

XIX yüzyılın sonu XX yüzyılın başlarında Kafkasya'nın tüm bölgelerinde olduğu gibi Nahçıvan'da yaşayan Müslümanların eğitim sistemi okullardan ve medreselerden ibarettir. Bu dönemde-XIX yüzyılın 70'li yıllarından sonra hükümet Müslüman ruhani kurumları, özellikle de okul ve mədrəsələrə ait ayrıca kanun ve nizamname tasarladı. Çar hükümeti kendi hükümranlığını olabildiğince takviye daha fazla ruahnilərin etkinliğini kontrol altında saklamıştı.

Araştırmalara göre belirtebiliriz ki, Müslüman ruhaniliyinin esasnamesi ilk defa 1872 yılı Nisan ayının 5-de teyit edilmişti. Bu əsasnamədən sonra ruhsal işlerini yöneten ruhani liderlerinin görevleri qanuniləşdi. Ruhani idaresinin görevlerine ruhani okulları için program tertip etmek de dahil edildi. Bu əsasnamədən sonra cami okullarına gözlemlemek kaza axundların, cami okulları açmak ve kontrolü ise quberniya meclisine verildi. Bundan sonra çar hükümetinin okul ve mədrəsələrə karşı tutumu da değişti.

XIX yüzyılın sonu XX yüzyılın başlarında Nahçıvan bölgesinde faaliyet gösteren tüm okul ve medreseler Kafkasya'da eğitim çalışmalarına dair 1873 Kasım 22-de kabul edilmiş kanundan sonra daha çok gelişmiştir (Kafkas Eğitim Dairesi'nin Serencamları 1892: 89). Bu dönemde Nahçıvan bölgesinde maarifin seviyesini yükselten kanunlardan biri de 1874 yılı Kasım ayının 20-de kabul edilmişti. Bu kanunda okul ve medreseler halk okullar direksiyası inspektorunun kontrolüne verilmişti. Inspektorun görevleri aşağıdakilerden ibarettir: vermeli idi;

1. Mevcut okul ve medreselerde nüfusun vəsaitilə Rusça sınıfların açılmasına emir

2. Yeni okul ve medreselerin açılmasına sadece halkın malzemesi ve Rusça öğretmeninin olması şartıyla izin vermeli;

3. Məkəb ve medreselerde eğitimin yönüne dikkat vermeli, kullanılan ders kitaplarına kontrol etmeli, yabancı ülkelerden getirilen ders kitapları yasak etmeli;

4. Bu okulların sağlık intiyaçlarını ne derecede cevap vermelerine göz etmeli;

Not edelim ki, 1893 yılında okul ve mədrəsələrə ait başka yeni bir kanun da onaylanmıştır (Ahmedov 2000: 192). Bu kanun önündeki yasalardan biraz farklıydı. Öyle ki, bu kanunda Azerbaycanının tüm bölgelerinde olduğu gibi Nahçıvan bölgesinde faaliyet gösteren tüm okul ve medreseler formal olarak doğrudan valilere tabi edilmiştir. Valiler ise işlerinin çokluğunu bahane ederek okul ve medreselerin çalışmaları ile maraqlanmırdılar. Bu durumda okul ve medreselerin kendiliğinden etkinliği geniş boyutlara ulaşmıştır.

Bu dönemde medreseler okullardan bir basamak yukarı olarak görülüyordu. Daha net ifadeyle okullar şimdiki dönemle karşılaştırıldığında orta okulların, medreseler ise yüksek okulların işlevini yerine getiriyordu. Ayrıca okullar mədrəsələrə hazırlık oluşturuyordu. Ali ruhani eğitimi almak ve medreselerde eğitimlerini sürdürmek isteyen tüm gençlerin okullarda okumaları önemliydi.

XIX yüzyılın sonu $X X$ yüzyılın başlarında faaliyet gösteren okulların bir kısmı, medreselerin hemen hepsi camilere tabi edilmiş ve onlardan bağımlı olmuştur. Bu nedenle, ister 
okullarda, gerekse medreselerde çalışan öğretmenlerin önemli bir parçasını mollalar oluşturmuştur. Esasen bu okullar medrese binasının genelinde faaliyet göstermiştir. Çokta büyük olmayan, bir ve iki odadan oluşan okullar bazen mollanın evinde bulunuyordu. Bazen ise okullar nüfusun toplum halinde daha yoğun yaşadığı məhələlərdə kira alınan evlerde açılıyordu. Başlıca nedeni mollaların ticaret amacı için uygun koşullar araması idi. Profesör Rıfat Hüseyinzade bunu mollanın ders demekle beraber kendi güzeranını geçirmek ve yaşam koşullarını iyileştirmek amacıyla göstermiştir (Hüseyinzade 2005: 27).

Bu nedenle okul binaları ve eğitim odaları dikkat merkezinden dışında kalmıştır. Çünkü, bu okullarda sınıf odaları tam gigeyna kurallarına uygun olmamıştır. Odada temiz hava ve çocukların rahat görebilmeleri için aydınlatma sistemi yok derecesinde idi. Kış mevsiminde bu okullarda çocukların ders keçməklərində sorun yaşandığını belirtmiştir. Örneğin, okullarda kışın odaları ısıtmak için mangal yakıyorlardı. Mangal çıkan duman ise çocukların siniflerde rahat oturup ders geçmelerine engelliyordu.

Okulların sorunları sadece bunlarla sınırlı değildi. Öyle ki, okula gelen çocukların eğitiminde sınıflarında kuru yerlerde oturduklarına göre sık sık xəstələnirdlər. Bazen çocuklar hastalıklardan korunmak için kendileri ile beraber evlerinden getirdikleri ayrılmış ve palaz parçaları üzerinde oturuyorlardı. Ancak bu da çocukların xəstələnmələrinin önünü alamazdı. Fakat medreselerdeki koşullar okullara oranla biraz iyiydi. Çünkü, mədrsənin sınıf odaları geniş, havadar, aydınlık, temiz ve sıcak olurdu. Hatta, bazı mədrsələrdə sınıf odalarını iyi ısıtmak için buhar qızdırıcılarından da kullanılırdı. Ayrıca medreselerde pansionlar ve uzak bölgelerden gelen çocukların kalabilmeleri için Yurtlar da çalışmıştır.

XIX yüzyılın sonu XX yüzyılın başlarında Azerbaycan'da olduğu gibi onun ayrılmaz bir parçası olan Nahçıvan bölgesinde de faaliyet gösteren okullarda ve medreselerde iç kurallar fərqlənməmişdir. Okullarda ders yılının başlamasını ve sona ermesinin net vakti olmamıştır. Ayrıca okullara çocukların kabulü tüm ilboyu sürdürülmüştür. Öte yandan okullarda ders programı uygulama yapılmamış ve düzgün ders modu olmamıştır. Örneğin, okulda dersler sabah saat 7'de bazen de 8'de başalamış, öğle saat 2 den 3 e kadar devam etmişti. Bazı durumlarda biraz genç olan çocuklar saat 12-de eve bırakılıyordu. Çocuklara ders arası solunuma ise toplam bir saat olmak üzere 12 den 1'e gibi izin veriliyordu. Okullarda haftanın sadece cuma günü dinlenme günü olarak tayin edilmişti. $O$, biri gün konaklama yerine haftanın perşembe dersler tekrar geçiriliyordu. Okullarda okuyan çocukların say kökenine gelince biraz farklıydı. Yani okulların bazılarında çocukların sayısı 10 kişiden 100 kişiye kadar artabilir biliyordu. Başka bir kaynakta ise bu dönemde Nahçıvan ve Ordubad kentlerde yaşayan bazı saygın mollalar çeşitli evlerde kişisel olarak kendilerinin tesis ve idare ettikleri küçük okullarda ders geçtiği gösterilmiştir (Ahmedov 2014: 64).

XIX yüzyılın sonu $X X$ yüzyılın başlarında Nahçıvan bölgesinde faaliyet gösteren okullarda tek eğitim yaşının olmaması, çocukların yaş özelliklerinin dikkate alınmaması öğrenmenin ve eğitimin kalitesini de aşağı düşürmüştü.

XIX yüzyılın sonunu XX yüzyılın başlarında Nahçıvan bölgesinde faaliyet gösteren okul ve medreselerde çocukların yaş sınırı iki gruba bölünmüştür. Birinci gruba dahil olan okullarda 7-8 yaştan 16 yaşa kadar olan çocuklar ve gençler okuyordu. İkinci grup okullarda ise 15-16 yaş 30 ve daha fazla yaşı olan gençler ve genç eğitim görüyordu (Memmedov 2001: 31). 
Okul ve medreselerde okuyan çocuklar kendi yaş özelliklerine uygun sınıflara, grup ve yarımqruplara bölünmemesi eğitimin kalitesine doğrudan olumsuz etkilemiştir ve eğitimin seviyesini düşürmüştür. Mesele şuradadır ki, okullarda çalışan öğretmenlerin büyük kısmı din adamları teşkil etmesine rağmen derslerde allahın adı da hiç çekilmiyor veya tüm ders boyunca sadece bir kez anılıyordu. Aynı zamanda derslerde çocuklara bir tane bile dua öyrədilmirdi.

Okullarda eğitim daha bireysel şekilde yapılıyordu. Yani, her bir öğrenciye kişisel yanaşılır ve günlük ev ödevleri veriliyordu. Sınıfta her öğrenciyi bireysel olarak tek tek ders geçen mollanın yanına gelerek eski dersi konuşuyormuş ve yen ders hakkında bilgi alıyormuş. Derslerini zayıf bilen ya da hiç bilmeyen öğrencilere mollalar tarafından falaqqa vastəsilə çileler veriliyordu.

XIX yüzyılın sonu $X X$ yüzyılın başlarında Nahçıvan bölgesindeki okullarda ders veren öğretmenleri "molla", "Yazman", ve çok Zamanı "axund" adlandırmışlar. Gösterilen dönemde bu isimler büyük sosyal anlam taşıyordu. Çünkü, o dönemde molla ve Yazman adlarını en çok eğitimli adamlara demişler. Bu nedenle, nüfus eğitimli mollalara büyük umut beslemiştir. İşte nüfus kendi aralarındaki tartışmalı meselelerde bilavastə molalarda başvurmuşlardır. Öte yandan nüfus dilekçe ve mektup yazdırmak, sözleşme hazırlamak gerektiğinde mollalardan yardım istemişlerdir.

$\mathrm{Bu}$ dönemde mollaların yanında yardımcı olarak çalışan kişileri ise öğretmen adlandırmışlar. Bildiğimiz gibi okulların bir çok bölümü medreselerin bünyesinde faaliyet göstermiştir. Böyle olduğu halde molla medresedeki çocuk bakım ile, öğretmen, yani onun yardımcısı ise medrese bünyesinde faaliyet gösteren okullardaki çocukların dersleri ile meşgul olurdu. Mollalar sadece okuldaki çocukların sayısı 30'u geçtiğinde o zaman kendisine yardımcı (öğretmen) tutuyordu. Bazı kaynaklarda bu yardımcılar (öğretmenler) "halife" de adlandırılmıştır (Caferov 2011: 25). Bu halifeleri mollalar çok zaman kendi okullarını bitirmiş bilgili ve yetenekli öğrenciler arasından seçirmiş. Halifelerin görevleri göre okula yeni giren küçük yaşlı çocukların disiplini ile uğraşmak ve onları okulun iç kuralları ile tanıştırmak idi. Profesör Rıfat Hüseyinzade araştırmalarından anlaşılıyor ki, okullarda çalışan halifelere mollalar 30 kuruştan 1 manata kimi haftalık maaş ödüyordu (Hüseyinzade 2005: 97). Bazı zamanlarda okullarda çocukların sayısı az olurdu. Bu durumda halife görevini okulu bitirmiş yaşlı öğrenci gerçekleştiriyordu.

XIX yüzyılın sonu XX yüzyılın başlarında Nahçıvan bölgesinde faaliyet gösteren tüm okullar paralı olmuştur. Ancak, somut belirlenen aylık eğitim hakkı olmamışıdır. Nahçıvan Özerk Cumhuriyeti Devlet arşivindeki belgelere istinaden diyebiliriz ki, okullarda eğitim gören çocuklardan haftada 5 YTL'den 20-25 kuruşadek eğitim hakkı alınırmış (Nahçıvan Özerk Cumhuriyeti Devlet Arşivi F.19, siy.2, iş 1197: 3-7). İşte bu nedenle, mollalar ayrıca maaş almırdılar. Onlar yalnızca ebeveynlerin ödedikleri aylık eğitim hakları ile ötüşməli oluyorlardı. Bazı ebeveynlerin paraya gücü yetmediği halde onlardan paranın yerine evlerinden getirdikleri çeşitli çeşitli gıda ve hediyeleri kabul ediyorlardı. Bu ise o demektir ki, mollaların maddi durumları okullarındaki çocukların sayısından ve ailelerinin, yani ebeveynlerinin maddi durumundan asılı idi.

Okullarla ilgili bir konuyu da özellikle belirtmek istiyorum ki, XIX yüzyılın sonu XX yüzyılın başlarında Nahçıvan'da ve bölgelerinde faaliyet gösteren okulların birçoğunda somut belirlenen eğitim süresi olmamıştır. Sadece eğitim süresi okullarda eğitim gören çocukların öğrenme 
qabliyyətindən ve yetisinden bağımlı olmuştur. Odur ki, öğrencinin eğitimini sık veya geç başa vurması özünden asılı idi. Yani öğrenci okulu iyi oxuyanda 6 ile, zayıf oxuyanda ise 8 ile başa vururdu.

\section{MESCID OKULLARI}

Söylenenlerden anlaşılıyor ki, eğitimde bu tür eksikliklerin olmasının başlıca nedeni mescitlerin yönetimi için belirlenmiş nizamnamenin uygulanmaması idi. Mollalar kendi üzerinde kontrol olmadığını bildikleri için medreseleri istedikleri gibi idare ediyorlardı.

XIX yüzyılın sonu XX yüzyılın başlarında Nahçıvan'da faaliyet gösteren okullarda eğitim kursunu onun içeriğine ve süresine göre koşullu olarak üç döneme ayrılabilir:

1. Alfabe ile Kuran'ın okunması ile tanışma;

2. Fars dili ve edebiyat ile tanışma;

3. Arap sarf-nəhvinin öğretilmesi;

Not edelim ki, okullarda öğretim için çocukların yaş ve bilgi düzeyi dikkate alınmış bir müfredat ve programı olmamıştır. O zaman böyle bir soru ortaya çıkıyor. Bir okulda müfredat ve programı olmadığı halde dersler nasıl yapılmıştı? Bu soruya cevap olarak diyebiliriz ki, evet okul ve medreselerde eğitim programı spontan şekilde, okullara rehberlik eden kişilerin bağımsız fikirleri ve mülahazaları temelinde düzenlenmiştir. Okul medreselerdeki öğretim diline gelince geçmişte olduğu gibi XIX yüzyılın sonu XX yüzyılın başlarında Arap ve Fars dilleri esas öğretim dili olmuştur. Nüfusun temel eğitim sistemi ise okuma yazmaktan ibaret idi.

Genel olarak alındığında XIX yüzyılın sonu XX yüzyıın başlarında Nahçıvan bölgesinde faaliyet gösteren tüm okul ve medreselerde esasen "çereke" denilen ders kitabı okunması ile başlanırmış. Bu kılavuz eğitim harf-hece adları prensip ile hazırlanan ve Ortaçağ Arap alfabesi ile yazılmıştır.

Not edelim ki, bu dönemde Çarlık Rusya Azerbaycan'ın diğer bölgelerinde olduğu gibi Nahçıvan kazasında da devlet okulları açmaya başlamıştı. Fakat diğer bölgelerde olduğu gibi Nahçıvan kazasında da açılan bu okullarda öğretmen eksikliği sorunu vardı. Bildiğimiz gibi açılan her devlet okulunun gelişimi becerikli ve bilgili yerel öğretmen kadrolarından çok bağımlı idi. Bu işin üstesinden gelebilecek yeterli pedagojik eğitim görmüş yerel öğretmen kareleri yetişməmişdi.

XIX yüzyılın sonu XX yüzyılın başlarında Nahçıvan'da maarifin gelişmesine engel olan bir çok nedenler vardı. Bu nedenlerin başında çarizimin halk maarifi alanındaki gerici politikaları dururdu. Kaynaklara baktığımızda görürüz ki, o dönemdeki çar yönetiminin bu çirkin siyasetini hatta çar memurlarının kendileri de itiraf etmişlerdir. Onlar bu haqqda yazıyordu: "Nahçıvan'da maarifin işini ləngindən konulardan başlıcası halk okullarının düzenlenmesi için maddi baza, eğitim binaları ve yerel becerikli öğretmen kadrolarının hemen hemen çok az sayıda olmasıdır" (Ahmedov 2000: 47; Caferov 2011: 123).

XIX yüzyılın sonunda Nahçıvan bölgesinde derslerin yapılması için uygun eğitim binalarının ve okulların maddi içinde olmaması maarifin gelişimini olumsuz etkilemiştir. Çünkü, bu dönemde öğrencilerin normal ders geçebilmesi için gigeynik taleplere uygun bir bina bulmak veya yeni okul inşa olmuyordu. Bunun ise başlıca nedeni okul binalarının inşası için çar yönetimi 
tarafından ayrılan paranın az olması ve öğrencilerden toplanan eğitim hakkının gerekli düzeyde olmaması bu dönemde Nahçıvan kazasında okulların inşa edilmesine imkan vermiyordu. Bazen açılması öngörülen okullar mesnetsiz nedenlerle açılışı ya geçişdirilmiş, ya da ki, ertelenmiştir.

XIX yüzyııın sonu XX yüzyılın başlarında Nahçıvan bölgesinde devlet okullarının azınlık etmesinin temel nedenlerinden biri de gösterilen dönemde çar yönetiminin halk maarifine az malzeme ayırması idi. Örneğin, 1867-1868-ci ve 1873-1874-cü tedris yıllarında Kafkasya'nın tüm bölgelerinde faaliyet gösteren tüm ilköğretim halk okullarına çar hükümetinin hazinesinden 75 bin manatdan az bir malzeme ayrılmıştır.

XIX yüzyıın sonu XX yüzyılın başlarında faaliyet gösteren okulların bir kısmı, medreselerin neredeyse hepsi camilere teslim edilmiş ve onlardan bağımsız olmuştur. Bu nedenle, gerek okullarda, gerekse medreselerde çalışan öğretmenlerin temel bir parçasını mollalar olmuştur. Esasen bu okullar medrese binasının içinde faaliyet göstermiştir. Çokta büyük olmayan, bir ve iki odadan oluşan okullar bazen mollanın evinde bulunuyordu. Bazen ise okullar nüfusun toplum halinde daha yoğun yaşadığı məhələlərdə kira alınmış evlerde açılıyordu. Bunun temel nedeni mollaların ticaret amacı için uygun ortamın bulunması idi. Prof. Rıfat Hüseyinzade bunu mollanın ders vermekle beraber kendi yaşamını geçirmek ve yaşam koşullarının iyileştirilmesi amacıyla ettiğini göstermiştir. Bu nedenle okul binaları ve eğitim odaları dikkat merkezinden uzakta kalmıştır. Çünkü, bu okullarda sınıf odaları tam gigeyna kurallarına uygun olmamıştır. Odada temiz hava ve çocukların rahat görebilmeleri için ışıklandırma sistemi yok derecesinde idi. Kış mevsiminde bu okullarda çocukların ders almalarında sorun oluyordu. Örneğin, okullarda kışta evleri ısıtmak için mangal yaktılar. Mangaldan çıkan duman ise çocukların sınıflarda rahatça oturup ders vermelerine engel oluyordu.

Okulların sorunları sadece bunlarla da bitmiyordu. Nitekim okula gelen çocuklar eğitim sınıflarında kuru yerlerde oturdukları için sık sık xəstələnirdlər. Bazen çocuklar hastalıklardan korunmak için kendileri ile birlikte evlerinden getirdikleri adamış ve kilim parçaları üzerinde oturuyorlardı. Ancak bu da çocukların hastalanmasının önüne geçmeyi bilmezdi. Ancak medreselerdeki ortam okullara oranla daha iyiydi. Zira mədrsənin sınıf odaları geniş, havalı, ışıkı, temiz ve sıcak oluyordu. Hatta, bazı mədrsələrdə sınıf odalarını iyi ısıtmak için buhar kızgın da kullanılırdı. Ayrıca medreselerde pansiyonlar ve uzak bölgelerden gelen çocukların gala için yurtlar da faaliyet göstermişti.

XIX yüzyılın sonu XX yüzyılın başlarında Azerbaycan'da olduğu gibi onun ayrılmaz bir parçası olan Nahçıvan bölgesinde de faaliyet gösteren okullarda ve medreselerde iç kurallar ayrımamıştır. Okullarda ders yılının başlamasının ve sona ermesinin net vakti olmamıştır. Ayrıca okullara çocukların kabulü tüm yıl boyunca devam ettirilmiştir.

XIX yüzyılın sonu $X X$ yüzyılın başlarında Nahçıvan'da maarif gelişmiş, bilimsel gelişiminde geleneksel okulların, özellikle de cami ve mescitlerin tarihi rolü büyük olmuştur. Bu dönemde sanayi, halk tarım ve ekonominin tüm alanlarında olduğu gibi, halk maarifi ve okul yapılanması alanında da büyük bir dönüm oluşmuştur. Öyle ki, Nahçıvan'da halk marifinin hızla gelişmesi ve meydana gelen yeni okullar kendi kaderinin sahibi olan zehmetkes halka bilime ve bilgiye ulaşabilmek imkanı kazandırmıştır. 


\section{KAYNAKLAR}

CAFEROV, H. R. Nahçıvan'da eğitim: gelişme yolu ve imkanları. Bakü: Bilim ve eğitim, 544 s. AHMEDOV, H. M. XIX yüzyıl Azerbaycan məkbəti. Bakı: Maarif, 366 s.

AHMEDOV, H. M. Azerbaycan okul ve pedagojik fikir tarihi. Yükseköğretim kurumlarının bakalavriat seviyesinde eğitim alan öğrenciler için ders kitabı. Bakü: Bilim ve eğitim, $432 \mathrm{~s}$.

Hüseyinzade R. L. Erken Ortaçağ döneminde Azerbaycan'da okul ve pedagojik fikir. (VII-XI yüzyıllar). Bakü: MBM, 272 s.

Kafkas Eğitim Dairesi'nin Serencamları. Tiflis: 1892, № 12.

MEMMEDOV ,V. S. Celil Memmedquluzade adına Nahçıvan Devlet Öğretmenler İnistitutu. Bakü: Çenlibel, $220 \mathrm{~s}$.

Nahçıvan Özerk Cumhuriyeti Devlet Arşivi: F.19, siy.2, iş 1197, v.3-7. 